\title{
CHANGES IN TARIFF PRICES FOR ELECTRICITY CONSUMPTION AND ITS IMPACT ON THE ENERGY SYSTEM
}

\author{
M.Muratov $^{1}$, K.Sh.Kadirov ${ }^{1}$, A.P.Kushev ${ }^{1}$ \\ 1“Uzbekenergo” JSC Scientific and Technical Center” LLC, Muxtor Ashrafiy, St., 9-A.
}

\begin{abstract}
Currently, the system of various tariffs on electricity consumption is widely used in almost all countries of the world. There is also a special role of tariffs on the change of modes of the energy system, which directly has its place in the smooth operation of the loading cycle of the system. The article discusses how to reduce the period of support for differentiated tariffs on electricity consumption over time.
\end{abstract}

Keywords: differentiated tariff on time, energy system regime, electricity, consumers.

\section{Introduction}

At the moment, the one-rate tariff system is the most common type of tariff system in the whole world. Such a tariff system carries out the calculation only for the specified price per $1 \mathrm{kWh}$ of consumed electricity. The price of electricity consumed by consumers is divided into one or several types, which means that the prices allocated to different states in different types of tariffs system.

The set prices for such tariffs and the periods in which electricity is consumed do not ensure the smooth operation of the loading cycle of the energy system. In addition, a single-rate tariff system and the energy system has its effect in the morning and evening "rush" periods.

Numerous criteria for determining power systems and consumer performance have been proposed [1, 2, 3, 4 , 5]. While the overall performance for them all involves the development of the system and the consumer enterprise in different ways, they are based on minimizing development costs. For example, it has been proposed to minimize costs, although foreseeing similar energy effects in determining the development of energy systems.

He also [6], suggested that object refinement be integrated and comprehensive. Integration Defining the main criteria during the activity cycle of the object is based on the integration criteria (integration) at all stages of the activity. That is, it takes into account technological process parameters, operating modes, schemes, equipment, and design.

As a criterion for the efficiency of electric energy consumers, the reduction of energy costs is envisaged by using differentiated tariffs.

\section{Methods}

In the event of constant supply of electricity, costs and accidents should not cause damage to onsumers in the energy system.

The cost of electricity consumption is expressed as follows:

$$
\mathrm{E}_{\mathrm{C}}=\mathrm{R}_{\mathrm{cl}} \cdot \alpha, \text { or } \mathrm{E}_{\mathrm{C}}=\mathrm{M}_{\mathrm{cc}} \cdot \mathrm{c},
$$

Here: $\mathrm{E}_{\mathrm{C}}$ - electricity consumption;

$\mathrm{R}_{\mathrm{cl}^{-}}$consumer load dependence ( $\left.\mathrm{kWh}\right)$;

$\mathrm{M}_{\mathrm{cc}}$ - the number of consumers connected to the power system;

$\alpha$ and $\mathrm{c}-1 \mathrm{~kW}$ power value or the price of a single Connected Consumer.

The advantage of single-rate tariffs is its extreme simplicity and the fact that it does not entail the need to use any measuring devices for consumers.

Payments for electricity consumed during the period of use of electricity tariffs at one rate are determined by one price, depending on the amount calculated for 1 $\mathrm{kW} \cdot \mathrm{h}$ :

$$
\mathrm{E}_{\mathrm{C}}=\mathrm{W} \cdot \mathrm{b}
$$

Here: $\mathrm{E}_{\mathrm{C}}$ - electricity consumption;

W-the amount of electricity consumed for the corresponding period (kWh);

$\mathrm{b}$-the cost of electricity is $1 \mathrm{~kW} \cdot \mathrm{h}$.

The increase in the expenditure on fuel resources in the production of electricity is also the reason for the change in the price of electricity. The fact that consumers of electricity produced do not consume all at once (during 24-hours), this causes an increase in the load on a certain period of the energy system. This can lead to early failure cases of equipment in the power system, and sometimes even accident cases. 
In this case, it is advisable to gradually introduce different tariffs for electricity. At the same time, in developed countries, the energy system is shifted to differentiated system of tariffs for the uniform distribution of electricity consumption to eliminate load periods. These tariffs at the same time are used in a variety of modes of consumption of electricity meters. The value of electricity consumed in three stages $\left(E_{C}\right)$ is determined by the following expression:

$$
\text { range of }\left\{\begin{array}{l}
W_{1} \leq W \leq W_{2} \Rightarrow E_{\mathrm{C}}=W \cdot b_{1} \\
W_{2} \leq W \leq W_{3} \Rightarrow E_{\mathrm{C}}=W \cdot b_{2} \\
W_{3} \leq W \leq W_{4} \Rightarrow E_{\mathrm{C}}=W \cdot b_{3}
\end{array}\right.
$$

Here: $\mathrm{W}$ - the total volume of electricity consumed for the period under consideration;

$\mathrm{b} 1, \mathrm{~b} 2, \mathrm{~b} 3-1 \mathrm{kWh}$ the price of the specified energy consumption for the corresponding range.

For tariffs, different rates of energy consumption (energy prices) are established, among which there is a link:

b1 $>$ b2 $>$ b3.

The use of tariffs with the help of a counter means a change in its total cost $\left(\mathrm{E}_{\mathrm{C}}\right)$ and the cost of $1 \mathrm{kWh}$ (cost), depending on the volume of consumed electricity, is shown in Figure 1.

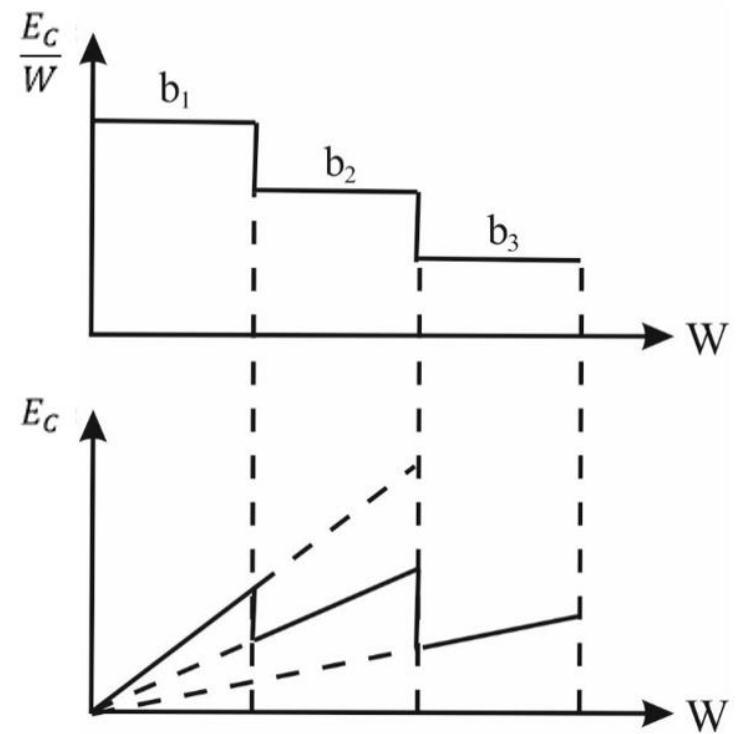

1-picture. The use of the tariffs by the meter will change the total cost of electricity $\left(E_{C}\right)$ and the cost (cost) per $1 \mathrm{kWh}$, depending on the amount of electricity consumed.

Using this tariff, the total cost of electricity consumed $\left(\mathrm{E}_{\mathrm{C}}\right)$ is determined the following expression:

$$
\begin{gathered}
E_{\mathrm{C}}=b_{1} W_{1}+b_{2}\left(W_{2}-W_{1}\right)+\ldots+b_{i}\left(W_{i}-W_{i-1}\right)+ \\
b_{n}\left(W_{n}-W_{n-1}\right)
\end{gathered}
$$

Here: $\mathrm{W}$ - the total volume of electricity consumed for the period under consideration;

$\left(W_{2}-W_{1}\right)$ - part of energy consumption in general consumption;

$b_{1}, b_{2}, \ldots b_{n}-1 k W h$ the price of the specified
In such a tariff, it is necessary to set the cost of 1 $\mathrm{kWh}$ of electricity for different periods differently. The reason should be a specific feature of each period. For example, it will be possible to set the cost of electricity for consumers in the low period of loading of the energy system with the prices that are stimulated.

Uzbekistan's electricity is one of the important sectors of the economy, which plays a very important role in the country's economic complexes. Almost all primary fuels (coal, oil, fuel oil) produced in the energy of Uzbekistan produce electricity for some neighboring countries. Therefore, the problems of rational use of energy resources, reduction of energy losses in the process of its production, processing, transmission and consumption are important and relevant for the energy sector of Uzbekistan.

The successful solution of the problems largely depends on the opportunities for the formation and support of energy-saving modes of production and transmission of electricity in the energy system, which significantly affects the non-uniformity of the demand for electricity by consumers [1].

A distinctive feature of any electrical energy system is the strict compliance of the volumes of production of this electrical energy with its consumption [2, 3]. A reliable energy system should ensure uninterrupted energy supply and demand balance.

At the same time, the consumption table is complemented by guaranteed supply sources from the source of electricity generation accordingly. In the event that principle is disrupted, the frequency of the alternating current network and the calculated voltage level in the power system will change, which will lead to either the failure of consumers or the early failure of production, transmission and distribution equipment as well as the electrical construction of consumers $[2,4]$

Uzbekistan has a total electricity production capacity of 14 thousand megawatts, of which 86 percent corresponds to the contribution of thermal power plants (2019).

However, 84 percent of the power of thermal power plants was launched almost half a century ago, with existing power plants operating 83 percent. In developed countries, 240-260 grams of fuel is spent for the production of 1 kilowatt of energy, while in some countries a thousand, unfortunately, 2 times more fuel is spent.

As a result of the development of economic sectors, demand for electricity can reach 20 thousand Megawatts by 2030 .

In Uzbekistan, electricity is produced mainly by activate of natural gas. In today's conditions with limited gas resources, it is said that by 2030 year to spend it even more - to overfill a very large amount of irreparable natural resources, that is, activate it cheaply.

The launch of atomic electricity will be one of the revolution solutions to reduce power consumption, but it still needs 8-10 years to do so. Therefore, it will be necessary to quickly eliminate the existing problems and radically develop the network, most importantly, in a short period of time to ensure significant positive changes in the system. 
energy consumption for the corresponding range.

At present, the issue of the adoption of electricity produced by private enterprises into the energy system has not been resolved. For example, 60 percent in Turkey, 20 percent in Korea, electricity is produced by private enterprises.

At the same time in the Republican energy system, electricity consumers are divided into: population, construction, industry, transport, agriculture and communal household consumers. Because these consumers electricity consumption is different, they come up with uneven loading graphics in the energy system. Therefore, in all countries of the world, uneven loading graphics in the energy system is a specific problem [2].

Specifically, such pricing was introduced in the late 1950 s in several European countries, including the FSA, Switzerland, Greece, Italy, Finland and France [5].

The production of the distance from the customer, the price of electric power established in coordination with the Ministry of Finance.

\section{Results and Discussions}

Studies of processes have shown that the linear programming method is highly effective.

The linear programming method has been developed to solve economically feasible problems in finding more convenient ways of distributing limited production resources. In this method, many mathematical links are expressed linearly. Typical production problems in linear programming include the goal, maximum benefit, or minimum cost. In most cases, the goal can be clarified based on specific circumstances.

In Uzbekistan, the prices of electricity, which range from production to consumption, are determined by the Ministry of Finance in conjunction with supplier companies.

The cost of electricity supplied to the population has been revised annually by two time in the last 7 years, with the exception of only 2017 year. In most cases, prices have increased from 5 percent to 12 percent. Only in 2013 year 15 percent, and the last time increased by 18 percent (figure 2 ).

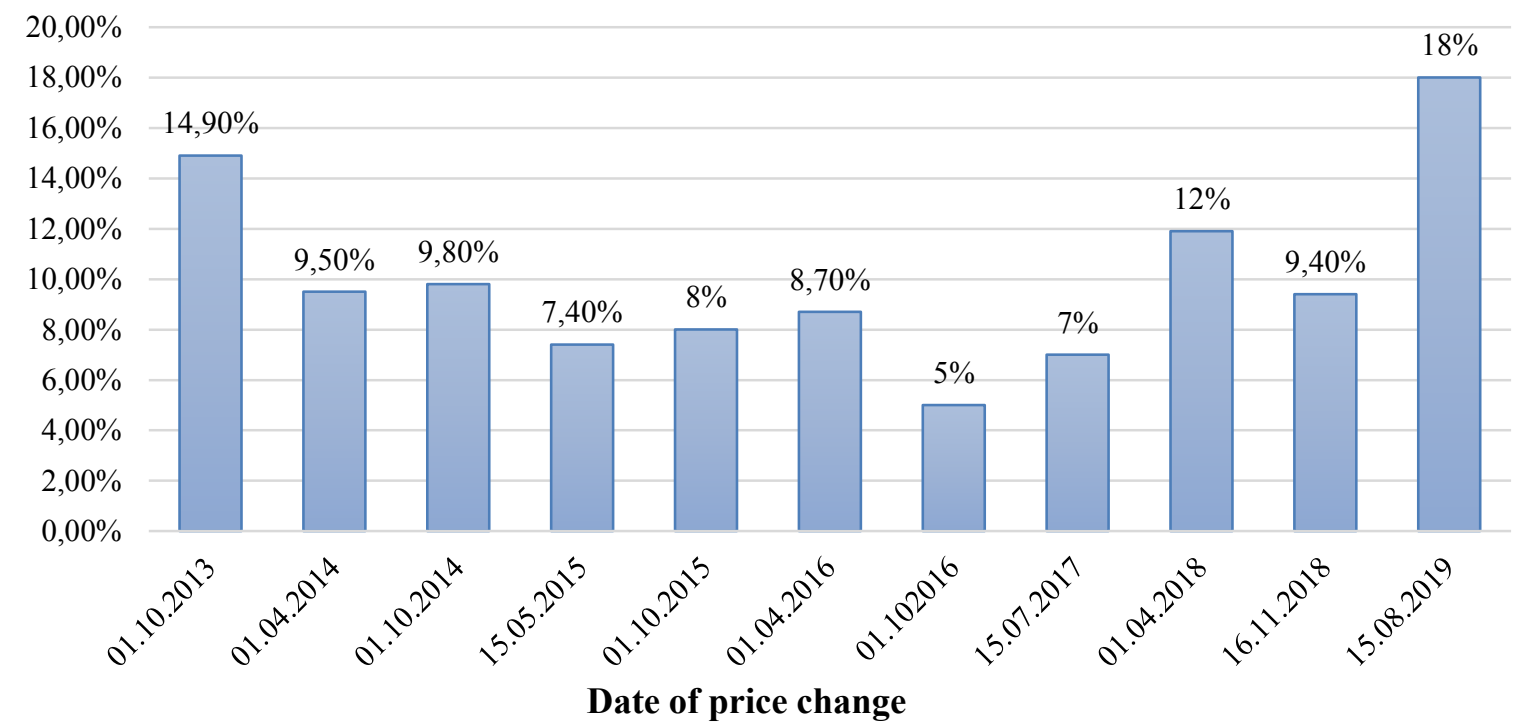

2-picture. Dynamics of prices for electricity in the population for 2013-2019 years in terms of changes (in\%)

In the case of October 1,2012 , the cost of $1 \mathrm{kWh}$ of electricity in the population was set to 104.40 soums, this indicator was set to 295 soums by August 15, 2019.

3 shows the dynamics of electricity prices of the population in 2014-2019,\% as of August 15, each year.

If we look at the annual dynamics of electricity prices (according to the case of 15 August of each year), it can be seen that in the period from 2014 year to 2019 year, prices have grown by at least 12 percent annually. In the last 7 years, a record increase in electricity prices was observed in the last year - 29 percent.

In August 15, 2012, the cost of $1 \mathrm{kWh}$ of electricity for the population was 97.5 soums. For the last 7 years, this figure has increased by 3 times.
Currently, the fact that the energy system is not enough power to start quickly the operation mode from the reserve in the summer and winter days, as well as the amount of electricity change significantly. Therefore, the energy system is not always able to satisfy the demand of consumers for electricity, which changes rapidly and significantly during the day.

At the same time, the provision of the necessary balance of electricity production and consumption in the unified energetic system of Uzbekistan is provided by the energy blocks of the IES and HPS, which significantly complicates the working modes of the energy system, that is, the control of the supervisory staff. 


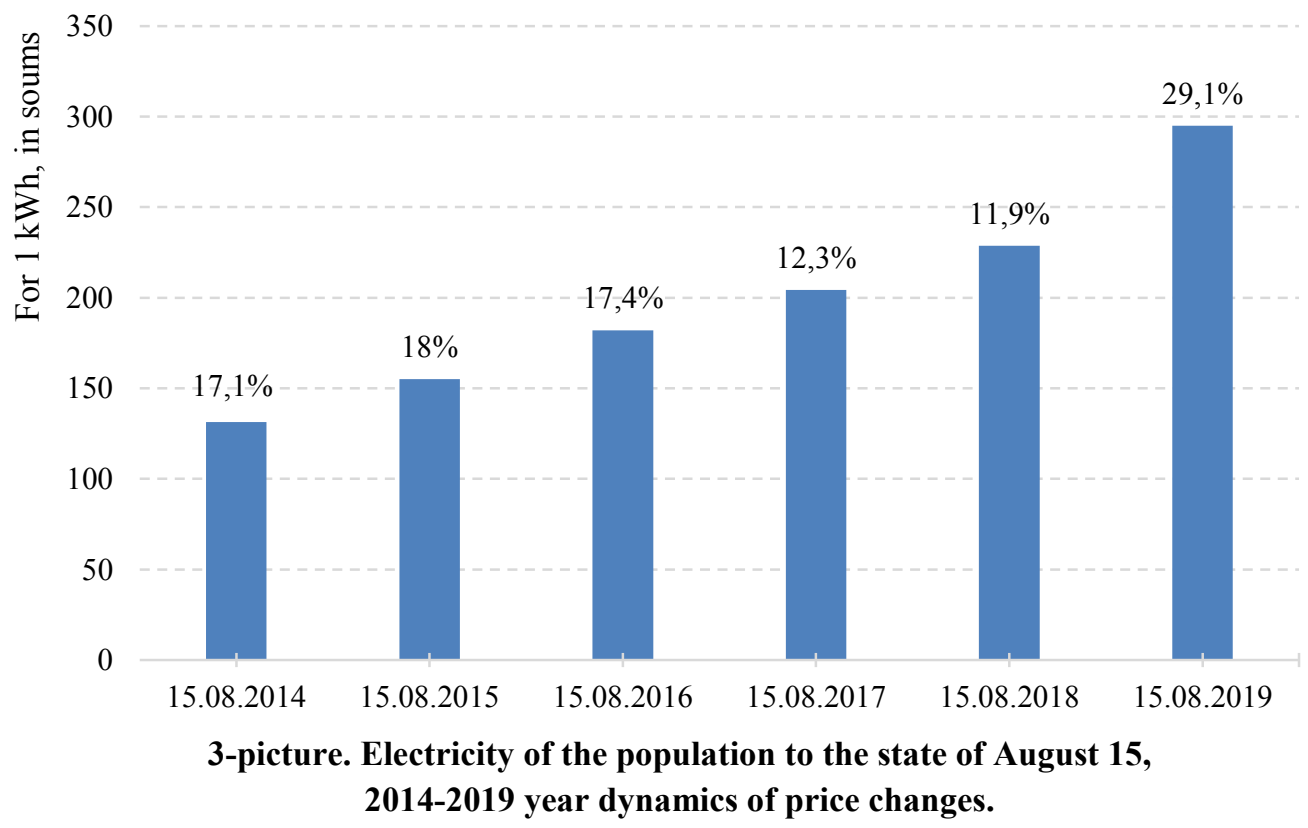

The term increase in demand for power will cause a portion of consumers to disconnect from the network. Because it is not technically possible (if any) to start the HPS extra blocks quickly. For this, as a rule, it takes at least 3-4 hours, sometimes even longer

Undoubtedly, limiting the consumers' demand for electricity will inevitably lead to a decrease in the production of electricity, that is, the deterioration of existing production equipment. Compulsory firing of consumers and limitation of their demand for electricity leads not only to great economic damage and social problems in the consumers, but also in the energy industry. In particular, it is necessary to provide employees of the suspended energy blocks with work, to pay them a salary for the period of their work on a mandatory basis, to compensate for the additional costs for keeping the switched off power blocks in working condition, etc.

\section{Conclusions}

It should also be noted that in the regulation of the loading period of the energy system, the power blocks of thermal power circuits work in non-energy-efficient modes at the same time night period. This will also significantly increase their specific fuel consumption. The cost of fuel used in such modes is also growing day by day. This is because the amount of fuel consumed during the loading period is also higher than the nonload period.

In addition, the natural depreciation of the main means of IAS and their replacement for a new one has not been practically done. Uzbekistan has not yet built new IAS in the coming years. Only the existing ones are slowly being modernized. The GES of the country has also faced a difficult situation, their existing equipment has also been in operation since 20-40 years, and they are also being modernized.
The uneven graphics caused by the consumption of consumers in the "rush" period lead to increased energy costs for the production, transmission and distribution of electricity. The application of a differentiated tariff on time is recommended to reflect the changes in these costs at different time intervals: at different times of the day, on the days of the week and on the seasons of the year. The fact that the support of these tariffs changes the modes of consumption of electricity by consumers also directly affects the change of operating modes of the energy system.

\section{References}

1. A.N. Ved, A.I. Mekhed, K.M. Efimova, Research of influence of power system on the stability and safety of operation of nuclear power plants / ICST. //. Ядерн та радіційна безпека. - 2010. - №2. - С. 32-36 p.

2. V.A. Malyarenko I.E. Nechmoglod Unevenness of the load schedule of the power system and ways of its alignment / // Svitlotekhnika TA elektroenergetika. 2011. - №4. - P. 61-69.

3. E.V. Gushchina Improving energy efficiency by regulating energy consumption modes. // Youth and science: Collection of materials of the VI all-Russian scientific and technical conference of students, postgraduates and young scientists [Electronic resource]. Krasnoyarsk: Siberian Federal UniversityT. 2011.

4. V.I.Gordeev Regulation of the maximum load of industrial electric networks. - Moscow: Energoatomizdat, 1988. - 186p.

5. V.V. Mikhailov Tariffs and modes of power consumption. - 2nd ed., pererab. and additional / / Moscow: Energoatomizdat, 1986. -216 p.

6. A.A. Pospelov, G.V. Ledukhovsky, A.A. Borisov. On taking into account the influence of non-uniformity of daily schedules of electric load when calculating the nominal specific fuel consumption for power units. / / / Vestnik IGEU-2008-. № 4. - P. 1-4. 